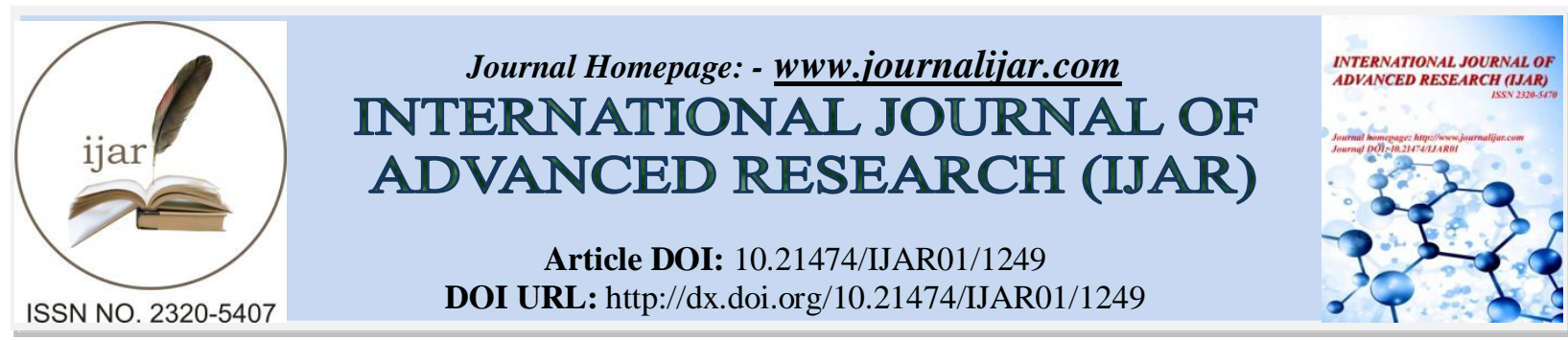

RESEARCH ARTICLE

\title{
IMPACTS OF THE FOOD ADDITIVE BENZOIC ACID ON LIVER FUNCTION OF WISTAR RATS.
}

\section{Mahmoud. M. Hassan ${ }^{1}$, Muawia I. A. Abdelgadir (Elrrigieg) ${ }^{2}$, Murwan K. Sabahelkhier ${ }^{3}$ and Omer F. Idris $^{3}$.}

1. Department of Food technology, Faculty of Agricultural technology and Fish Sciences, El Neelain University, Khartoum, Sudan.

2. Department of chemistry, Faculty of Science, University of Bakht El - Ruda, Eld - Dueim, Sudan.

3. Department of Biochemistry and molecular biology, Faculty of Science and Technology, El Neelain University, Khartoum, Sudan.

\section{Manuscript Info}

[.........................

Manuscript History

Received: 16 June 2016

Final Accepted: 18 July 2016

Published: August 2016

Key words:-

food additive; benzoic acid; ALT; Lethal oral dose; histopathological changes; atrophy; hyperemia; toxicological data.

\section{Abstract}

This study was aimed to assess liver function of Wistar rats affected by oral ingestion of different doses of the food additive benzoic acid using rats' serum ALT as an indicator. 48 male Wistar rats were divided into 4 groups (12 rats for each). One group served as control, and the remainder of the 3 groups received different doses of benzoic acid. Animals were put in quarantine for one week in Meck Nimir Research Center, Khartoum, Sudan. Animals were freely accessed to standard diet and tab water. Doses were once daily, orally administered for 28 days. A significant $(\mathrm{p} \leq 0.05)$ gradual increase (according to increased treatment doses) in serum alanine amino transferase was observed in treated animals, compared with control. Liver sectioning was made to prepare slides. There were different observed signs of liver histopathological changes, in all treated animals, compared to control. These changes included: atrophy, hyperemia, vacuolation of cytoplasm, large vacuole (completely empty spaces) inside the cells and also there is the coagulative diffuse necrosis, inflammatory cells focal around some blood vessels, and haemosiderosis. Animals showed no non-significant weight loss or increase. It is concluded that oral ingestion of benzoic acid results in liver dysfunction confirmed by increased serum ALT concentrations So it is preferred to try to decrease ingestion of foods and beverages in which benzoic acid is a constituent. This study was focused on evaluating adverse liver changes, influenced by oral ingestion of benzoic acid as food additive.

Copy Right, IJAR, 2016,. All rights reserved.

\section{Introduction:-}

Benzoic acid and sodium benzoate are being considered together because it is undissociated benzoic acid that is responsible for its antimicrobial activity. As benzoic acid itself is only slightly soluble in water, sodium benzoate which, under acid conditions, converts to undissociated benzoic acid - is often used instead. Benzyl acetate, its 
hydrolysis product, benzyl alcohol, and the oxidation product of this alcohol, benzaldehyde, are extensively metabolized to benzoic acid in experimental animals and humans. Therefore, toxicological data on these precursors were also utilized in the assessment of the potential health effects of benzoic acid. Benzoic acid and sodium benzoate are used as food preservatives and are most suitable for foods, fruit juices, and soft drinks that are naturally in an acidic $\mathrm{pH}$ range. Their use as preservatives in food, beverages, toothpastes, mouthwashes, dentifrices, cosmetics, and pharmaceuticals is regulated. The estimated global production capacity for benzoic acid is about 600000 tons per year. Worldwide sodium benzoate production in 1997 can be estimated at about 55 000-60000 tones. Benzoic acid occurs naturally in many plants and in animals. It is therefore a natural constituent of many foods, including milk products. Anthropogenic releases of benzoic acid and sodium benzoate into the environment are primarily emissions into water and soil from their uses as preservatives. Concentrations of naturally occurring benzoic acid in several foods did not exceed average values of $40 \mathrm{mg} / \mathrm{kg}$ of food. Maximum concentrations reported for benzoic acid or sodium benzoates added to food for preservation purposes were in the range of $2000 \mathrm{mg} / \mathrm{kg}$ of food. After oral uptake, benzoic acid and sodium benzoate are rapidly absorbed from the gastrointestinal tract and metabolized in the liver by conjugation with glycine, resulting in the formation of hippuric acid, which is rapidly excreted via the urine. To a lesser extent, benzoates applied dermally can penetrate through the skin. Owing to rapid metabolism and excretion, an accumulation of the benzoates or their metabolites is not to be expected. In rodents, the acute oral toxicity of benzoic acid and sodium benzoate is low (oral LD 50 values of $>1940 \mathrm{mg} / \mathrm{kg}$ body weight). In cats, which seem to be more sensitive than rodents, toxic effects and mortality were reported at much lower doses (about $450 \mathrm{mg} / \mathrm{kg}$ body weight). Benzoic acid is slightly irritating to the skin and irritating to the eye, while sodium benzoate is not irritating to the skin and is only a slight eye irritant. For benzoic acid, the available studies gave no indication of a sensitizing effect; for sodium benzoate, no data were identified. In short-term studies with rats, disorders of the central nervous system (benzoic acid/sodium benzoate) as well as histopathological changes in the brain (benzoic acid) were seen after feeding high doses (>1800 mg/kg body weight) over 5-10 days. Other effects included reduced weight gain, changes in organ weights, changes in serum parameters, or histopathological changes in the liver. The information concerning long-term oral exposure of experimental animals to benzoic acid is very limited, and there is no study available dealing specifically with possible carcinogenic effects. From a limited four-generation study, only a preliminary no-observed-(adverse-) effect level (NO (A) EL) of about $500 \mathrm{mg} / \mathrm{kg}$ body weight per day can be derived. With sodium benzoate, two long-term studies with rats and mice gave no indication of a carcinogenic effect. However, the documentation of effects is inadequate in most of these studies; therefore, no reliable NO (A) EL values can be derived. Data on its precursors support the notion that benzoic acid is unlikely to be carcinogenic. In humans, the acute toxicity of benzoic acid and sodium benzoate is low. However, both substances are known to cause non-immunological contact reactions (pseudo allergy). This effect is scarce in healthy subjects; in patients with frequent urticaria or asthma, symptoms or exacerbation of symptoms was observed. A provisional tolerable intake of $5 \mathrm{mg} / \mathrm{kg}$ body weight per day can be derived, although benzoates at lower doses can cause nonimmunological contact reactions (pseudo allergy) in sensitive persons (Maki and Suzuki, 1985). Although undissociated benzoic acid is the more effective antimicrobial agent for preservation purposes, sodium benzoate is used preferably, as it is about 200 times more soluble than benzoic acid. About $0.1 \%$ is usually sufficient to preserve a product that has been properly prepared and adjusted to $\mathrm{pH} 4.5$ or below (Chipley, 1983). Benzoic acid is a colorless crystalline solid and a simple aromatic carboxylic. The name is derived from gum benzoin, which was for a long time it's only known source. Benzoic acid was discovered in the sixteenth century. The dry distillation of gum benzoin was first described by Nostradamus (1556), and then by Alexius Pedemontanus (1560) and Blaise de Vigenère (1596). Benzoic acid occurs naturally in many plants and it serves as an intermediate in the biosynthesis of many secondary metabolites. Salts of benzoic acid are used as food preservatives and benzoic acid is an important precursor for the industrial synthesis of many other organic substances. The salts and esters of benzoic acid are known as benzoates (Neumüller, 1988). Benzoic acid and its salts are used as a food preservatives, represented by the E-numbers E210, E211, E212, and E213. Benzoic acid inhibits the growth of mold, yeast and some bacteria. It is either added directly or created from reactions with its sodium, potassium, or calcium salt. The mechanism starts with the absorption of benzoic acid into the cell. If the intracellular $\mathrm{pH}$ changes to 5 or lower, the anaerobic fermentation of glucose through phosphofructokinase is decreased by $95 \%$. The efficacy of benzoic acid and benzoate is thus dependent on the $\mathrm{pH}$ of the food (Pastrorova et al., 1997). Acidic food and beverage like fruit juice (citric acid), sparkling drinks (carbon dioxide), soft drinks (phosphoric acid), pickles (vinegar) or other acidified food are preserved with benzoic acid and benzoates. Typical levels of use for benzoic acid as a preservative in food are between $0.05-0.1 \%$. Foods in which benzoic acid may be used and maximum levels for its application are controlled by international food law. Concern has been expressed that benzoic acid and its salts may react with ascorbic acid (vitamin C) in some soft drinks, forming small quantities of benzene. Benzoic acid is present as part of 
hippuric acid ( $N$-benzoylglycine) in urine of mammals, especially herbivores (Gr. hippos $=$ horse; ouron = urine). Humans produce about $0.44 \mathrm{~g} / \mathrm{L}$ hippuric acid per day in their urine, and if the person is exposed to toluene or benzoic acid, it can rise above that level (Krebs et al., 1983). Benzoic acid is relatively nontoxic. It is excreted as hippuric acid (Bindu Nair, 2001). Benzoic acid is metabolized by butyrate-CoA ligase into an intermediate product, benzoyl-CoA, which is then metabolized by glycine $\mathrm{N}$-acyltransferase into hippuric acid. Benzoic acid occurs naturally as do its esters in many plant and animal species. Appreciable amounts have been found in most berries (around $0.05 \%$ ). Ripe fruits of several Vacciniumspecies (e.g., cranberry, V.vitismacrocarpon; bilberry, V.myrtillus) contain as much as $0.03-0.13 \%$ free benzoic acid. Benzoic acid is also formed in apples after infection with the fungus Nectriagalligena. Among animals, benzoic acid has been identified primarily in omnivorous or phytophageous species, e.g., in viscera and muscles of the Rock Ptarmigan (Lagopusmuta) as well as in gland secretions of male muskoxen (Ovibosmoschatus) or Asian bull elephants (Elephasmaximus).Gum benzoin contains up to $20 \%$ of benzoic acid and $40 \%$ benzoic acid esters (Tomokuniand, 1972). For humans, the World Health Organization's International Programme on Chemical Safety (IPCS) suggests a provisional tolerable intake would be $5 \mathrm{mg} / \mathrm{kg}$ body weight per day. Cats have a significantly lower tolerance against benzoic acid and its salts than rats and mice. Lethal oral dose for rats is $3040 \mathrm{mg} / \mathrm{kg}$, and for mice it is 1940-2263 mg/kg (Bedford and Clarke, 1972). ALT is a transaminase enzyme (EC 2.6.1.2), which is found in serum and in various bodily tissues, but is most commonly associated with the liver. It catalyzes the two parts of the alanine cycle. It catalyzes the transfer of an amino group from alanine to $\alpha$-ketoglutarate, the products of this reversible transamination reaction being pyruvate and glutamate.

Glutamate + pyruvate $\leftrightarrow \alpha$-ketoglutarate + alanine

It is commonly measured clinically as a part of a diagnostic evaluation of hepatocellular injury, to determine liver health. When used in diagnostics, it is almost always measured in international units/liter (U/L) While sources vary on specific normal range values for patients, 10-40 U/L is the standard normal range for experimental studies (Wang et al., 2012). Significantly elevated levels of ALT often suggest liver damage, bile duct problems, so, ALT is commonly used as a way of screening for liver problems (Paul and Giboney, 2005). Cats have a significantly lower tolerance against benzoic acid and its salts than rats and mice. Lethal dose for cats can be as low as $300 \mathrm{mg} / \mathrm{kg}$ body weight. For humans, the World Health Organization's International Programme on Chemical Safety (IPCS) suggests a provisional tolerable intake would be $5 \mathrm{mg} / \mathrm{kg}$ body weight per day. Cats have a significantly lower tolerance against benzoic acid and its salts than rats and mice. Lethal oral dose for rats is $3040 \mathrm{mg} / \mathrm{kg}$, and for mice it is $1940-$ $2263 \mathrm{mg} / \mathrm{kg}$ (Bedford and Clarke, 1972). In Taipei, Taiwan, a city health survey in 2010 found that $30 \%$ of dried and pickled food products had too much benzoic acid, which may affect the liver (Chen and Kao, 2010).

\section{Methodology:- \\ Biologic experiment:-}

48 male Wistar rats (weight ranged from $200-240 \mathrm{~g}$ ), were divided into 4 groups (12 rats for each). All animals were provided the standard diet, composed of: (beef meat $10.6 \%$, sesame oil $46.6 \%$, corn flour $42.4 \%$, and table salt $0.29 \%$ ). All rats were put in quarantine for seven days. All animals were liberally accessed to standard diet and tab water. One group was put as control. The remainder 3 groups, received 5, 1000 and $2000 \mathrm{mg} / \mathrm{kg} \mathrm{b.w} \mathrm{of} \mathrm{benzoic} \mathrm{acid,}$ once daily. Animal's weight was taken once weekly. Ingested doses were justified according to (Bedford and Clarke, 1972), and (Wibbertmann et al., 2000). In short-term studies with rats, high doses (>1800 mg/kg b.w) of (benzoic acid/sodium benzoate) were administered over 5-10 days (Wibbertmann et al., 2000). Blood sampling was done initially, on the $14^{\text {th }}$ day and on the $28^{\text {th }}$ day. Blood samples were taken from rats' eyes using capillary tubes, into suitable labeled blood containers, then centrifuged at $30000 \mathrm{rpm}$ then serum was kept at $5^{\circ} \mathrm{C}$. By the 28 th day. All animals were sacrificed by the end of the experiment, and then liver organs were taken, labeled then kept in $10 \%$ formal/saline solution. Photomicrographs were prepared according to method described by (Bancroft and Gamble, 2002).

\section{Measurement of ALT concentration:-}

Working solution was prepared by adding $2 \mathrm{ml}$ from reagent 1 (buffer, lactate dehydrogenase LDH, L alanine, pH 7.8 ) and $500 \mu \mathrm{l}$ from reagent 2 (substrate $\alpha$-ketoglutarate). Working solution was mixed and put in $37^{\circ} \mathrm{C}$, $1 \mathrm{ml}$ was taken from working solution then $100 \mu \mathrm{l}$ from serum was added, mixed and incubated at $37^{\circ} \mathrm{C}$ for 1 minute. Initial absorbance was read, at 1 minute intervals, the difference between absorbance were calculated. The average absorbance difference per minute: $\Delta$ A / minute $\times 1750$ (factor) $=\mathrm{U} / \mathrm{L}$ (Murray, 1984). A calibrated spectrophotometer (Awareness Technology, model No. 1904 plus, serial No. 1904-5252) was set for measurement of serum ALT concentrations. 


\section{Photo micrographic Techniques:-}

Wistar rat liver were collected in clean, sterilized containers (from autopsied animals), labeled, cleaned with distilled water and preserved in $10 \%$ formal saline. Preparation of slides was done as follows:

1 .

Portions of gills, skeletal muscle and liver were cut into small pieces. The cut tissues were dehydrated in solutions of $30 \%$ alcohol for two hours, then solutions of 50\% alcohol for two hours, finally $70 \%$ alcohol for two hours to attain the preservation level.

2. Continuation of dehydration: $70 \%$ alcohol (twice $1 / 4$ an hour, 1/4 an hour), $90 \%$ alcohol / 2 hours, $95 \%$ alcohol / 2 hours, $100 \%$ alcohol / 1 hour, $100 \%$ alcohol / 1 hour.

3. Clearing: Xylene 1/3/4 an hour, Xylene 2/1/2 an hour Or Chloroform overnight.

4. Impregnation: Wax $1 / 1$ hour, Wax $2 / 1$ hour.

5. $\quad$ Embedding: Tissue is embedded in cassette.

$6 . \quad$ Section: Microtome was used.

7. $\quad$ Mounting on slides: Formaldehyde and gelatin were used.

8. Wax fixation and tissue elongation: Slides were put on oven, temperature $<45^{\circ} \mathrm{C}$.

9. Wax removal: Xylene $1 / 2$ minutes, Xylene $2 / 2$ minutes, Absolute alcohol 1/ 2 minutes, Absolute alcohol 2 / 2 minutes, 90 \% Alcohol / 2 minute, 70 \% Alcohol / 2 minutes, Distilled water / 2 minutes.

10.

Staining: Stain with iodine and haematoxillin for 10 minutes.

11. Blueing: Wash under running tab water if overstrained dip quickly in acid alcohol (3 drops of $\mathrm{HCl}$ in $70 \%$ alcohol), then Distilled water / 1/2 minute, Iodine / 1/2 minute, Distilled water / 1/2 minute, $70 \%$ alcohol / 1/2 minute, $90 \%$ alcohol / 1/2 minute, Absolute alcohol 1/1/2 minute, Absolute alcohol 2 / 1/2 minute, Xylene 1/ 1/2 minute, Xylene 2/ 1/2 minute.

12.

Covering with Canada balsam (Bancroft and Gamble, 2002).

\section{Statistical analysis:-}

All values were express as Means \pm Sd. The SPSS one - way Anova test was used for the evaluation of differences between Wistar rats groups according to dose. The differences were considered significant if a P. value was less than 0.05 .

\section{Results and discussions:- Toxicological study:-}

In this study, oral administration of doses of 5, 1000 and $2000(\mathrm{mg} / \mathrm{kg} \mathrm{b} . \mathrm{w})$ of benzoic acid resulted in significant $(\mathrm{p} \leq 0.05)$ gradual increase in serum ALT (Table 1), according to increased doses of ingested benzoic acid. However, the low dose of $(5 \mathrm{mg} / \mathrm{kg} \mathrm{b.w})$, \{which is within the tolerable intake of $5 \mathrm{mg} / \mathrm{kg} \mathrm{b}$.w per day can be derived, although benzoates at lower doses can cause non-immunological contact reactions (pseudo allergy) in sensitive persons (Maki and Suzuki, 1985) \}, resulted in mild serum ALT increase, compared with control. The highest activities of ALT were found in hepatocytes. Therefore, increased serum ALT activity can accompany hepatocellular injury or necrosis with cell injury or death. Determination of ALT activity is a relatively sensitive indicator of hepatic damage. Mechanisms of increased activity of ALT in serum include enzyme release from damaged cells or induction of enzyme activity exercise (Paul, 2005). Release of ALT from the cytosol can find secondary to cellular necrosis, or as a result of cellular injury with membrane damage (Figlio et al., 2004). Elevations in serum ALT activity are considered to be relatively specific for liver disease (Stockham and Scott, 2002).After oral ingestion of benzoic acid and sodium benzoate in experimental animals or humans, there is rapid absorption of the undissociated benzoic acid from the gastrointestinal tract. The substances are metabolized in the liver mainly by conjugation with glycine, resulting in the formation of hippuric acid, which is rapidly excreted via the urine. With oral LD50 values of $>1940 \mathrm{mg} / \mathrm{kg}$ body weight, the acute toxicity of benzoic acid and sodium benzoate in rodents is low. Studies concerning short-term, sub chronic, or chronic oral exposure conducted according to current guidelines are not available for benzoic acid or sodium benzoate. Effects on the central nervous system, weight gain (in several cases without reduced food intake), and liver and kidney were recorded at high concentrations of both compounds. As expected, and as far as it is possible to conclude with the limited database, toxic effects and effect levels seem to be similar for both compounds. A preliminary NO (A) EL of about $500 \mathrm{mg} / \mathrm{kg}$ body weight per day (the highest dose tested) may be derived based on a limited four-generation study (Kieckebusch and Lang, 1960). This is supported by two short-term studies in which no adverse effects were observed at the highest tested dose levels of 647-825 mg/kg body weight per day (Kreis et al., 1967; Bio-Fax, 1973) and by the fact that no serious side effects have been reported after therapeutic use of sodium benzoate at a dose level of 250-500 $\mathrm{mg} / \mathrm{kg}$ body weight per day in humans, although occasionally anorexia and vomiting were observed. It was found 
that $30 \%$ of dried and pickled food products had too much benzoic acid, which may affect the liver (Chen and Kao, 2010). Groups of 4-5 male and 4-5 female rats received 0, 1, 2, 4, and $8 \%$ sodium benzoate equivalent to 640, 1320, 2620 , and $6290 \mathrm{mg} / \mathrm{kg}$ bw/d in the diet for 90 days. $4 / 8$ animals died (average 13 days to death) in the $8 \%$ dose level group, the average weight gain of the surviving rats was reduced and the relative liver and kidney weight was significantly increased with histopathological changes in liver and kidney ( $2.6 \mathrm{~g} / \mathrm{kg}$ bw/d) (Moreno, 1977). Treated animals showed significant $(\mathrm{p} \leq 0.05)$ body weight decrease, compared to control. This is in agreement with (Moreno, 1977). Cases of urticaria, asthma, rhinitis, or anaphylactic shock have been reported following oral, dermal, or inhalation exposure to benzoic acid and sodium benzoate. The symptoms appear shortly after exposure and disappear within a few hours, even at low doses (Maibachand Johnson, 1975).

Table 1:- Effects of different doses (in $\mathrm{mg} / \mathrm{kg}$ b.w) of benzoic acid on rats' serum ALT in IU/L.

\begin{tabular}{|l|l|l|l|l|}
\hline $\begin{array}{c}\text { Goses } \\
\text { Croups }\end{array}$ & Control & Initial & $14^{\text {th }}$ day & $28^{\text {th }}$ day \\
\hline 5 & $28.33 \pm 7.25^{\mathrm{a}}$ & $32.50 \pm 7.05^{\text {N.S }}$ & $155.75 \pm 19.96^{\mathrm{b}}$ & $319.08 \pm 22.14^{\text {bc }}$ \\
\hline 1000 & $28.92 \pm 6.32^{\mathrm{a}}$ & $30.42 \pm 6.99^{\text {N.S }}$ & $234.58 \pm 10.71^{\mathrm{c}}$ & $383.00 \pm 18.55^{\text {d }}$ \\
\hline 2000 & $30.42 \pm 5.92^{\mathrm{a}}$ & $33.17 \pm 6.71^{\text {N.S }}$ & $377.67 \pm 17.59^{\mathrm{d}}$ & $538.83 \pm 30.18^{\mathrm{e}}$ \\
\hline
\end{tabular}

Values are means \pm SD. Means with rows not sharing common letter $(\mathrm{s})$ are significantly different $(\mathrm{P}<0.05)$. N.S $=$ non- significant.

\section{Liver dissection:-}

All plates show transverse sections of rats' liver. Plate A represents control, whether plates B, C and D represented animals treated by 5,1000 and $2000 \mathrm{mg} / \mathrm{kg}$ body weight of benzoic acid respectively. Plate B, showed nearly normal pattern, according to the tolerable ingested dose of $5 \mathrm{mg} / \mathrm{kg}$ body weight of benzoic acid per day (Maki and Suzuki, 1985). But plate C indicated: atrophy, slight hyperemia, no black material inside kupfler, cell, and vacuolation is more appeared large vacuole (completely empty spaces) inside the cells and also there is the coagulative diffuse necrosis and inflammatory cells focal around some blood vessels in liver. Plate D showed hyperemia, haemosiderosis, necrosis and vacuolation of cytoplasmic cells and no inflammatory cells. Histopathological changes were observed in plates C through D, that represented animals treated with 1000 , and $2000 \mathrm{mg} / \mathrm{kg}$ bw/day. Study liver abnormalities are confirmed by (Moreno, 1977), stated that, groups of 4-5 male and 4-5 female rats received 0, $1,2,4$, and $8 \%$ sodium benzoate equivalent to $640,1320,2620$, and $6290 \mathrm{mg} / \mathrm{kg} \mathrm{bw} / \mathrm{d}$ in the diet for 90 days. $4-8$ animals died (average 13 days to death) in the $8 \%$ dose level group, the average weight gain of the surviving rats was reduced and the relative liver and kidney weight was significantly increased with histopathological changes in liver and kidney $(2.6 \mathrm{~g} / \mathrm{kg} \mathrm{bw} / \mathrm{d})$. Also study results are in agreement with (Chen and Kao, 2010), who stated that in Taipei, Taiwan, a city health survey in 2010 found that $30 \%$ of dried and pickled food products had too much benzoic acid, which may affect the liver. Study results were confirmed by (Fujitani, 1993), who conducted an experiment in rats received sodium benzoate for 10 days in feed. At doses of $1568 \mathrm{mg} / \mathrm{kg}$ body weight per day and above, changes in further serum parameters and an increased relative liver weight were described, accompanied by liver histopathological changes, also in several other studies, adverse effects were seen only at higher doses after feeding sodium benzoate over periods from 10 to 42 days, so that a lowest-observed- (adverse-) effect level (LO (A) EL) of $1358 \mathrm{mg}$ sodium benzoate/ $\mathrm{kg}$ body weight per day for short-term exposure can be derived. Cats have a significantly lower tolerance against benzoic acid and its salts than rats and mice. Lethal oral dose for rats is $3040 \mathrm{mg} / \mathrm{kg}$, and for mice it is $1940-2263 \mathrm{mg} / \mathrm{kg}$ (Bedford and Clarke, 1972).

Effects of oral ingestion of benzoic acid included reduced weight gain, changes in organ weights, changes in serum parameters, or histopathological changes in the liver. In humans, the acute toxicity of benzoic acid and sodium benzoate is low. However, benzoic acid, and sodium benzoate, is known to cause non-immunological contact reactions (pseudo allergy). This effect is scarce in healthy subjects; in patients with frequent urticaria or asthma, symptoms or exacerbation of symptoms was observed. A provisional tolerable intake of $5 \mathrm{mg} / \mathrm{kg}$ body weight per day can be derived, although benzoates at lower doses can cause non-immunological contact reactions (pseudo allergy) in sensitive persons (Maki and Suzuki, 1985). 


\section{Photomicrographs:-}

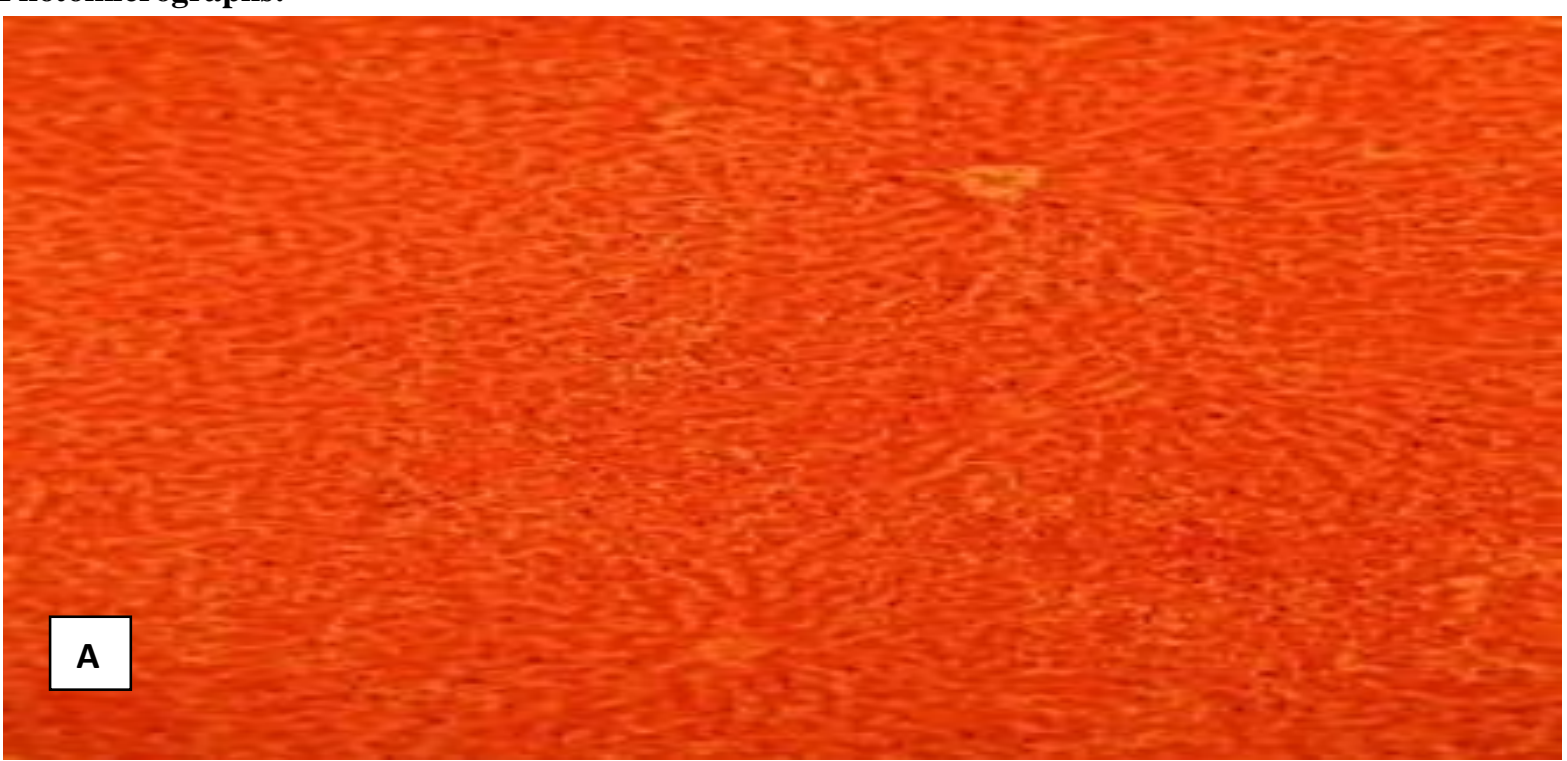

Plate A: - Transverse section of liver control (Eosin and haematoxilin $\times 1000)$.

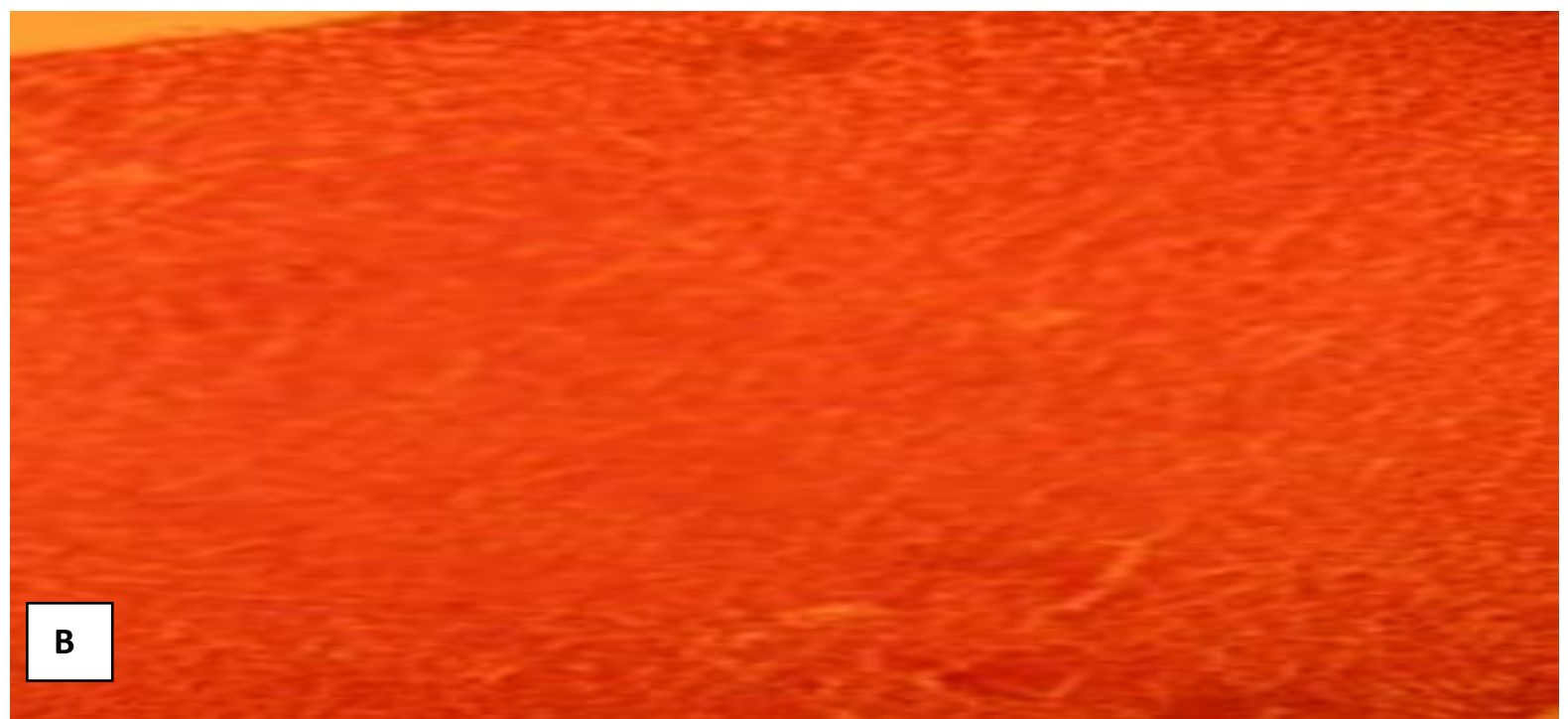

Plate B: - Transverse section of liver of rat treated with $5 \mathrm{mg} / \mathrm{kg}$ b.w of benzoic acid (Eosin and haematoxilin $\times$ 1000) 


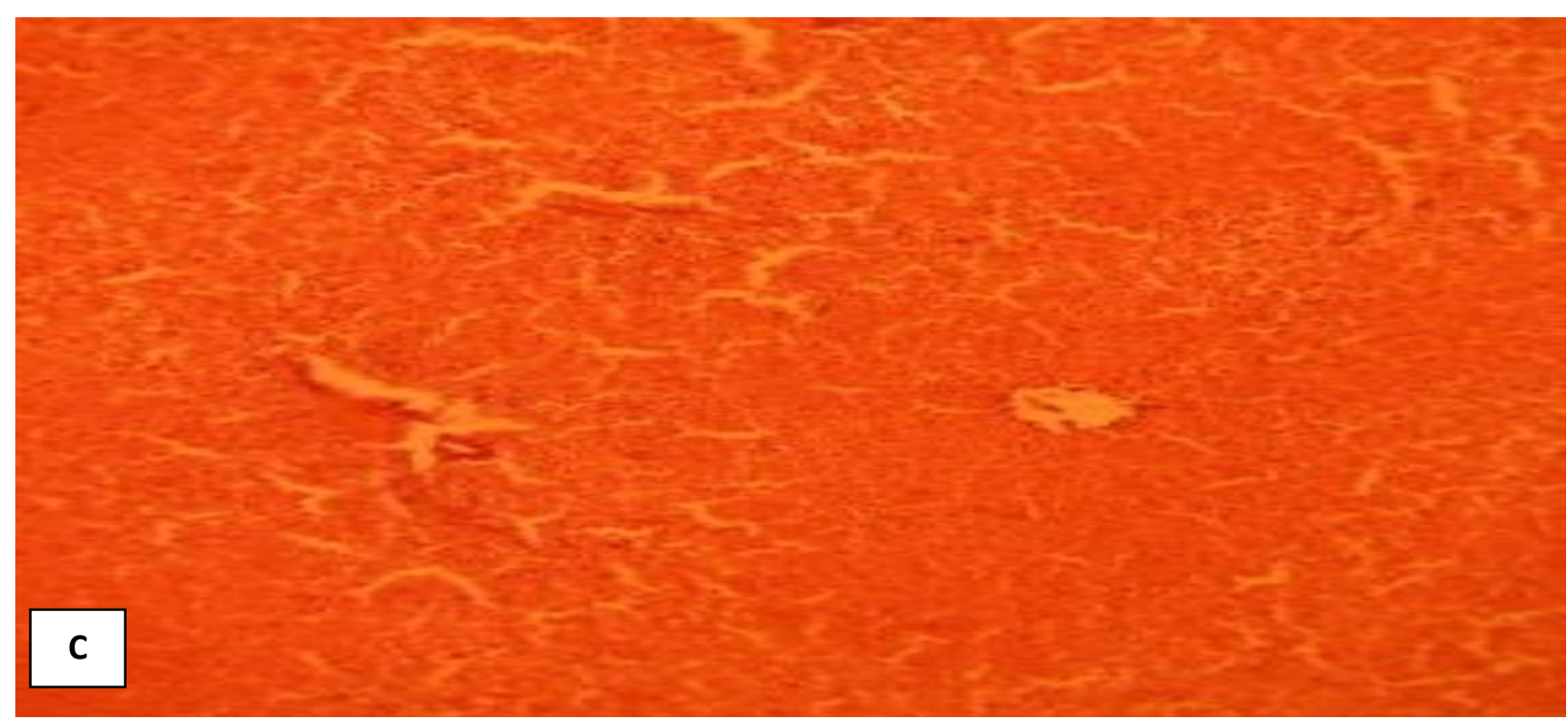

Plate C: - Transverse section of liver of rat treated with $1000 \mathrm{mg} / \mathrm{kg} \mathrm{b.w}$ of benzoic acid (Eosin and haematoxilin $\times$ 1000)

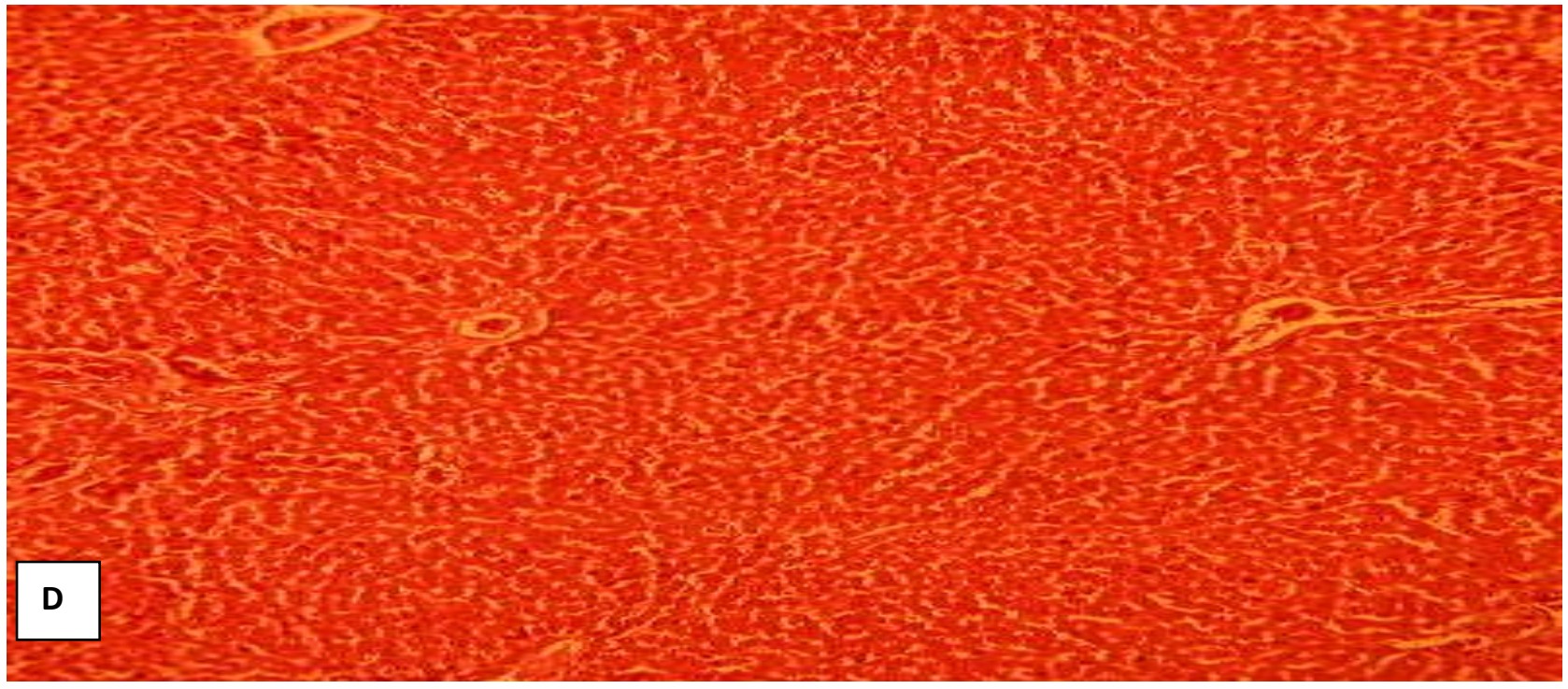

Plate D: - Transverse section of liver of rat treated with $2000 \mathrm{mg} / \mathrm{kg} \mathrm{b} . \mathrm{w}$ of benzoic acid (Eosin and haematoxilin $\times$ 1000).

\section{Conclusions:-}

According to the significant increase in serum ALT corresponding to increased doses of ingested benzoic acid, accompanied by the observed histopathological changes in plates $\mathrm{C}$ and $\mathrm{D}$, compared to control, it can be concluded that benzoic acid causes rats' liver dysfunction. Though it is recommended to limit ingest foods and beverages processed by benzoic acid or its derivatives such as sodium benzoate.

\section{Acknowledgments:-}

The author would like to express his sincere gratitude to Dr. Hind Errayah (Faculty of Veterinary Medicine, University of Sudan, Sudan) for her meaningful photographing and describing histopathological slides, and Family of Ed - Dueim Renal Renal Dialysis Center Lab. for providing seriobiochemical analysis. 


\section{References:-}

1. Bedford PG, Clarke EG (1972). Experimental benzoic acid poisoning in the cat. Vet Rec. 53-58. 90. 4672555. 3.

2. Bio-Fax (1973). Benzoic acid. Northbrook, IL, Industrial Bio-Test Laboratories, Inc.

3. Chen J, Kao YL (2010). "Nearly 30\% dried, pickled foods fail safety inspections"

4. Bindu Nair (2001). Cosmetic Ingredient Review Expert Panel "Final Report on the Safety Assessment of Benzyl Alcohol, Benzoic Acid, and Sodium Benzoate". Int. J. Tox. 20 (3): 23-50. doi: 10.1080/10915810152630729.

5. Figlio LD, Heather L, Tarpley DVM, Kenneth S, Latimer DVM, Perry J, Bain DVM (2004). Class of (Figlio) Department of Pathology (Tarpley, Latimer, Bain), College of Veterinary Medicine, University of Georgia, Athens, GA 30602-7388.

6. Juteau P, Valérie C, Marie-France D, Réjean B, François L, Richard VB (2005). "Cryptanaerobacterphenolicus gen. Nov., sp. Nov., an anaerobe that transforms phenol into benzoate via 4-hydroxybenzoate". Int.J.S.E.Met. 55 (1): 245-250. doi:10.1099/ijs.0.02914-0

7. Kieckebusch W, Lang K (1960). The compatibility of Benzoic acid imchronischen Fütterungsversuch. Drug Research.10:1001-1003.

8. Krebs HA, Wiggins D, Stubbs M (1983)."Studies on the mechanism of the antifungal action of benzoate" (PDF). Biochem. J. 214 (3): 657-663.

9. Kreis H, Frese F, Wilmes G (1967). Physiological and morphological scheVeränderungen to Rattennachperoraler Verabreichungvon benzoic acid. Food. Cosme. Toxico. 5: 505-511.

10. Maibach HI, Johnson HL (1975). Contact urticaria syndrome. Archives of dermatology, 111:726-730. Moreno OM (1977). Report to RIFM, 22 August. Cited in BIBRA Report Toxicity Profile - Benzoic Acid, TNO BIBRA Toxicology International Ltd. (1989).

11. Murray R, Kaplan MM, Gandolfo JV, Quaroni EG (1984). Aspartate amino transferase. Clin. Chem. The C.V. Mosby Co. St Louis. Toronto. Princeton, 1112-116.

12. Mustafa AA, Alamin SE (2004). Efficacy of Pendimethalin and Atrazine for Weed Control in Corn (ZeaMaysL.) In Sudan Electronic Theses and Dissertation. URN: uofketd-agr2003125. Faculty of Agriculture. Department of Crop Protection.

13. Neumüller OA (1988). Rompps Chemical Dictionary $\left(6^{\text {th }}\right.$ ed). Stuttgart: Frankh'sche Verlagshandlung. ISBN 3440-045 16-1.OCLC 50969944.

14. Paul P, Michelangelo A, Dorothea M, Irina S, Bünyamin T, José O, Alberto B (2007). "Analysis of pesticide residues using the Quick Easy Cheap Effective Rugged and Safe (QuEChERS) pesticide multiresidue method in combination with gas and liquid chromatography and tandem mass spectrometric detection". Anal Bioanal Chem. 389 (6): 1697-714.

15. Stockham SL, Scott MA (2002). Fundamentals of Veterinary Clinical Pathology. Ames, Iowa State University Press, 2002, pp. 434-459 U.S. Environmental Protection Agency (1984). Washington, D.C., EPA/600/X-84/211 (NTIS PB88129630), 1984.

16. Tomokuni K, Ogata M (1972). "Direct Colorimetric Determination of Hippuric Acid in Urine". Clin. Chem. 18 (4): 349-351. 